\title{
Domestic violence
}

\author{
A M B Golding FFPHM
}

J R Soc Med 2002;95:307-308

RSM CONFERENCE, MARCH 2002

According to the late John Bowlby ${ }^{1}$, human beings of all ages are at their happiest and able to employ their talents to best advantage 'when they are confident that, standing behind them, there are one or more trusted persons who will come to their aid should difficulties arise'. Yet for many the trusted friend they took on as a partner turns out to be a source of fear. Domestic violence can cause much distress and physical injury, and occasionally death. Typically the victim is seen on many occasions by health professionals before the cause of her troubles (it is a she in more than $90 \%$ of cases) is recognized. In March 2002, a multidisciplinary group met at the RSM to exchange ideas on how to recognize these patients sooner and manage them better. I briefly review some of the themes that emerged.

\section{Epidemiology}

The term domestic violence describes a continuum of behaviour ranging from verbal abuse, through threats and intimidation, manipulative behaviour, and physical and sexual assault, to rape and even homicide. Most such violence is perpetrated by men against women and children. Those who experience domestic violence often keep it to themselves - shamed and embarrassed by what is happening to them; unsure of where they can go and what help they can get, and fearful of doing anything that might make things worse ${ }^{2}$. Of a sample of 1035 women in Hackney, $17 \%$ had experienced physical violence during the previous year at the hands of a partner or former partner. The risk of violence was doubled in pregnancy (adjusted odds ratio $2.11)^{3}$. In a sample of pregnant women seen at Guy's and St Thomas' Hospitals, 7.8\% reported having been threatened with violence in the preceding twelve months ${ }^{4}$. In the first six months of 2001 the Metropolitan Police Service recorded 44476 allegations of domestic violence.

The 1997-99 Confidential Enquiry into Maternal Deaths in the UK, Why Mothers Die ${ }^{5}$, devoted a chapter to domestic violence. $45(12 \%)$ of the mothers who died had spontaneously told a health professional of violence experienced during their pregnancy. Mothers were not routinely asked about domestic violence so this is likely to be an underestimate. Mothers under 18 who died were

Section of Epidemiology \& Public Health, Royal Society of Medicine, 1 Wimpole Street, London W1G 0AE, UK

E-mail: agolding@cliftonhill.fsnet.co.uk particularly likely to have experienced domestic violence. The Confidential Enquiry urges all health professionals to make themselves aware of the importance of domestic violence in their practice and deal appropriately with these patients.

Domestic violence creates fear in the victim, who is humiliated, becomes less attentive to parenting and eventually neglects her child (Sturge C, personal communication). The boys are more likely to become violent themselves and the pattern is of a home where there is a high level of physical abuse (often including severe corporal punishment), an increased likelihood of sexual abuse and physical neglect. It is important to put in place systems which support the child and the resident parent. Child abuse is a risk factor for domestic violence - as is animal abuse, so the Royal Society for the Prevention of Cruelty to Animals may be a source of useful information.

\section{Identifying domestic violence}

Victims of domestic violence will often present in primary care with injuries they say are due to some accident; depression or self-harm are other manifestations. Typically the patient attends on several occasions with different but related troubles. Many health workers seem to fear that, if they ask about domestic violence, they will be opening a Pandora's box of problems they cannot sort out, so primary care staff not only require training in how to respond but also advice on where to refer patients ${ }^{6}$. Training is particularly required for professional staff in general practice, accident and emergency departments and antenatal clinics. All injuries that might be due to domestic violence must be documented in a way that enables the record to be used later in a court of law.

\section{Management}

Domestic violence is best managed by several agencies acting together, usually with social services in the lead. A common system for recording domestic violence is needed, since victims may be known to several agencies, none seeing the whole pattern.

The service partnership pioneered in Newham has shown the great advantage of bringing together the key service providers to achieve a coordinated response to the complex and varied needs of victims of domestic violence. 
This dedicated service decreases the amount of staff time needed to deal with the issues, and is important in building trust between the agencies, especially between social services and the police.

\section{Refuges}

The Women's Aid Federation of England (Women's Aid) coordinates a national network of over 250 local domestic violence refuge and support organizations that help over 53000 women and their children each year and offer outreach support to over 200000 abused women.

\section{The law}

Until quite recently it was believed that children would nearly always benefit from continued contact with both parents. Now, however, it has become clear that where the separation has been preceded by domestic violence, contact with the other parent (usually the father) can be dangerous to the child and residential parent. In the UK one woman is murdered every three days, sometimes as a result of contact arrangements set up by the courts. There are four key points the courts need to consider (Butler-Sloss, personal communication). They are:

- The extent of the violence

- The effect on the primary carer

- The effect on the child

- The ability of the offender to recognize his behaviour and attempt to change it.

The Court of Appeal considered four cases in 2000 where there had been domestic violence. It concluded as follows:

'On hearing a contact application in which the allegations of domestic violence were established, the court should consider the conduct of both parties towards each other and towards the children, the effect on the children and on the residential parent and the motivation of the parent seeking contact, ensuring as far as it could, that any risk of harm to the child was minimised and the safety of the child and the residential parent was secured'.

The court should consider whether contact is to be allowed and, if so, whether it should be supervised in a secure place. All too often contact has been arranged where there is inadequate supervision and the child has been harassed or abused without the intervention of any supervisor ${ }^{7}$.

\section{Prevention}

Schools offer an important opportunity for children from violent families to learn how to manage conflict in a non- violent environment. Non-violence should be on the agenda of meetings with new parents, general meetings and parents' meetings with class teachers or tutors. The school needs to publicize itself - through newsletters, notice boards and student diaries - as happy, orderly, positive and collaborative. This approach is not aimed exclusively at children from violent families, but will help them ${ }^{8}$. An example of such a scheme from Canada is the Youth Relationship Project. This is an 18 -session programme that uses a health promotion approach to preventing violence in 'dating' relationships. Teenage pupils learn how to deal with interpersonal problems without aggression. Having learned about the issues themselves they try to effect change within their peer groups and the broader community. There are three components - education and awareness of abuse and power dynamics in close relationships; skill development and social action. Fifteen groups (each with 6-10 participants of both sexes) were involved. After two years they showed less threatening behaviour to dating partners and perpetrated less emotional abuse than a control group $^{9,10}$.

\section{Conclusion}

Domestic violence is common and the victims often first present with health problems. Doctors, nurses and others working in primary care, accident and emergency departments and antenatal clinics in particular need training in its recognition and management.

\section{REFERENCES}

1 Bowlby J. Attachment and Loss: Separation Anxiety and Anger, Vol 2. Harmondsworth: Penguin, 1973:407

2 Department of Health. Domestic Violence: a Resource Manual for Health Care Professionals. London: DoH, 2001

3 Richardson J, Coid J, Petruckevitch A, Chung WS, Mooney S, Feder G. Identifying domestic violence: cross sectional study in primary care. BMJ 2002;324:274-7

4 Mezey GU. Economic and Social Research Council. An Exploration of the Prevalence, Nature and Effects of Domestic Violence in Pregnancy. London: ESRC, 2001

5 Confidential Enquiry into Maternal Deaths in the UK. Why Mothers Die. London: RCOG Press

6 Cann K, Withnell S, Shakespeare J, Doll H, Thomas J. Domestic violence; a comparative survey. Public Health 2001;115:89-95

7 Golding AMB. Parental contact and domestic violence. Health $\mathrm{Hyg}_{\mathrm{g}}$ 2000;21:149-51

8 Varnava G. Towards a Non-violent Society: Checkpoints for Schools. London: National Children's Bureau 2000

9 Wolfe DA, Jaffe G. Emerging strategies in the prevention of domestic violence. Future Children 1999;39:9:133-44

10 Wekerle C, Wolfe DA. Dating violence in mid-adolescence: theory, significance and emerging prevention initiatives. Clin Psych Rev 1999;19:435-56 